\title{
Reconfigurable Stationary Battery with Adaptive Cell Switching for Electric Vehicle Fast-Charging
}

\author{
Engelhardt, Jan; Gabderakhmanova, Tatiana; Rohde, Gunnar; Marinelli, Mattia
}

Published in:

Proceedings of the $55<$ sup $>$ th $</$ sup $>$ International Universities Power Engineering Conference 2020

Link to article, DOI:

10.1109/UPEC49904.2020.9209774

Publication date:

2020

Document Version

Peer reviewed version

Link back to DTU Orbit

Citation (APA):

Engelhardt, J., Gabderakhmanova, T., Rohde, G., \& Marinelli, M. (2020). Reconfiguraple Stationary Battery with Adaptive Cell Switching for Electric Vehicle Fast-Charging. In Proceedings of the 55 International Universities Power Engineering Conference 2020 IEEE. https://doi.org/10.1109/UPEC49904.2020.9209774

\section{General rights}

Copyright and moral rights for the publications made accessible in the public portal are retained by the authors and/or other copyright owners and it is a condition of accessing publications that users recognise and abide by the legal requirements associated with these rights.

- Users may download and print one copy of any publication from the public portal for the purpose of private study or research.

- You may not further distribute the material or use it for any profit-making activity or commercial gain

- You may freely distribute the URL identifying the publication in the public portal 


\title{
Reconfigurable Stationary Battery with Adaptive Cell Switching for Electric Vehicle Fast-Charging
}

\author{
Jan Engelhardt*, Tatiana Gabderakhmanova*, Gunnar Rohde ${ }^{\dagger}$, Mattia Marinelli* \\ * Department of Electrical Engineering \\ Technical University of Denmark (DTU) \\ Ris $\varnothing$ campus, Roskilde, Denmark \\ $\dagger$ Nerve Smart Systems ApS \\ Roskilde, Denmark \\ gr@nervesmartsystems.com
}

\{janen, tatigab, matm\}@elektro.dtu.dk

\begin{abstract}
In this study, we introduce a battery energy storage system (BESS) with reconfigurable cell topology as the direct power source for fast-charging of electric vehicles (EVs). In the proposed scenario, the BESS is following the charging request of the EV by changing its cell topology in a real time fashion. The BESS is modelled at the cell level in order to demonstrate the reconfigurable design, and linked with an EV model. The simulation results confirm that the BESS can maintain a balanced level of its cell states while following the voltage request of the EV with satisfactory precision. However, the approach of adaptive cell switching shows to be not sufficient for fulfilling the current request. Therefore, complementary solutions are necessary to achieve a suitable control of the charging current.
\end{abstract}

Index Terms-adaptive cell switching, battery energy storage system, electric vehicles, fast-charging, reconfigurable battery

\section{INTRODUCTION}

The transition towards a more environmentally friendly and sustainable use of energy is one of the main drivers for the electrification of the transport sector. Especially, in power systems with a high share of renewable energy, replacing fossil fuel powered vehicles by electric vehicles (EVs) is a promising option to reduce carbon emissions [1], [2]. However, the rising numbers of EVs pose new challenges for the electric power system, such as an overall increased energy demand, as well as congestion and voltage unbalances in the distribution grid [3], [4]. Specifically, fast-charging processes are impacting the grid due to the high peak-load demand and the inflexible charging times [5]. As part of the H2020 INSULAE project, we deploy and test a local DC microgrid consisting of renewable energy sources (wind, photovoltaics), a BESS, and a DC fast-charging station [6]. In this concept, the BESS provides temporal flexibility for integrating the renewables, and at the same time serves as a buffer during the fast-charging processes to decrease the impact on the connected AC distribution grid. Conventionally, the design of battery systems comprises multiple cells that are connected in a fixed topology. However, due to production tolerances and temperature gradients during

This work has received funding from the H2020 INSULAE project under the Grant Agreement No. 824433. The goal of the project is to provide innovative energy solutions for decarbonising European islands. For more information, visit http://insulae-h2020.eu/. operation, individual battery cells can show different characteristics and deviating ageing processes. These unbalance issues decrease the effective capacity of the whole battery, as charging and discharging processes are limited by the weakest cells. Moreover, cells with a lower capacity are more likely to be overcharged or overdischarged, which accelerates the ageing process further [7]. Eventually, faulty cells may cause the entire battery to become non-functional. In order to improve energy efficiency, reliability and life span of the battery, sufficient cell balancing techniques are required [8]. A promising solution is to design battery systems with a reconfigurable topology [9], [10]. The flexibility is achieved through power switches, which are used to bypass and engage complete battery cells. Therefore, the overall system performance is not limited by single cells since all battery cells are operated according to their individual performance.

In the present work we investigate, if the reconfigurable design of a stationary battery can further be used to directly follow the charging request of an EV by adapting the cell topology in a real-time fashion. While the concept of battery buffered fast-charging stations has already been analysed in literature, an external DC-DC converter is commonly used as a controllable interface to the EV [5]. To the best of our knowledge, no study has yet explored the option of charging an EV directly with a reconfigurable BESS, without any power converter interconnecting the two units. Utilizing the intrinsic controllability of a reconfigurable BESS could make power converters dispensable, thus decreasing power losses and investment costs for EV fast-charging. The aim of the paper is threefold. Firstly, to introduce a modelling approach that captures the proposed reconfigurable BESS design. Secondly, to demonstrate the performance of the BESS when following the charging request of an EV based on simulations. Thirdly, to discuss the limitations of the technology and give an outlook on how to improve the concept.

The rest of this paper is organized as follows. The proposed BESS design is described in section II. Section III is focused on the modelling approach and the control of the battery cells. The case study is characterized in section IV. Simulation results are presented and discussed in section V. Finally, relevant conclusions are drawn in section VI. 


\section{ReCONFIGURABle BATtery System}

In order to allow power transfer from the BESS to the $\mathrm{EV}$, both units are assumed to be provided with compatible equipment according to the charging standard IEC 61851, such as the correct type of connector and the ability to follow the same communication protocol [11]. The most important electronic peripheral device inside the BESS is the battery management system (BMS). It is responsible for ensuring safety and increasing reliability of a BESS as well as protecting individual cells inside the battery system. In the present work, we assume a series connection of all cells, as exemplified by the two cells shown in Fig. 1. To achieve a reconfigurable design, each cell is equipped with two power switches, e.g. metal-oxide-semiconductor field-effect transistors (MOSFETs). The switches are controlled by the BMS in order to either engage or bypass their respective cell without disconnecting the current path through the battery, as demonstrated for cell $i$ and cell $(i+1)$ in Fig. 1 .

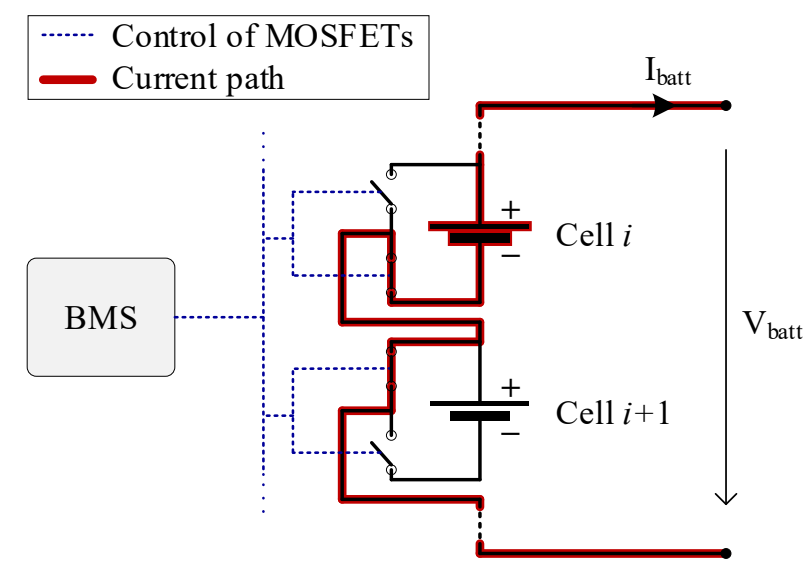

Fig. 1. Section of the proposed reconfigurable BESS design.

While the control approach is generally independent of the battery cell chemistry, lithium-iron phosphate (LFP) cells were chosen for the present analysis due to their almost constant voltage and resistance profiles for state-of-charge (SOC) values between $10 \%$ and $90 \%$. In order to stay in the linear region, we assume that the BESS will only be operated within the mentioned SOC range. More information on the cell specifications are provided in the following section, where we also introduce the control concept for deciding on the connection state of each individual cell.

\section{Modelling APPROACH}

To demonstrate the concept of the adaptive cell topology, a MATLAB \& Simulink ${ }^{\circledR}$ model of the BESS was developed. The BESS model was linked with an EV model in order to analyse the performance of the reconfigurable design for the EV fast-charging use case.

\section{A. General assumptions}

Fig. 2 provides an overview of the two models and their linkage. Both the BESS and the EV model consist of two submodels each. The first submodel is describing the behaviour of the respective BMS. The second submodel is representing the physical properties of the battery including the effects of charging and discharging on the battery state. To provide clarification, variables that refer to the BESS model have the superscript "BESS", and variables that refer to the EV model have the superscript "EV". If no superscript is given, the variable is a common representation that is applicable for both models.

The individual cells are modelled as a Thévenin equivalent containing two elements: the open-circuit voltage $V_{\text {oc,cell }}$ and the cell resistance $R_{\text {cell }}$. The cell voltage is therefore given as

$$
V_{\text {cell }}=V_{\text {oc,cell }}-I_{\text {cell }} \cdot R_{\text {cell }}
$$

where $I_{\text {cell }}$ is the cell current. For simplification purposes, thermal conditions are not considered in both models.

\section{B. BESS model}

In order to capture the reconfigurable design, each cell of the BESS model is modelled separately and can be identified by its cell number $i$. The cells were characterized in the laboratories of Nerve Smart Systems ApS in order to determine the SOC dependency of the cell open circuit voltage. For the present analysis, we assume a linear interpolation between $V_{\mathrm{oc}, \text { cell }}^{\mathrm{BESS}}=3.25 \mathrm{~V}$ and $V_{\mathrm{oc} \text {,cell }}^{\mathrm{BESS}}=3.35 \mathrm{~V}$, referring to SOC values of $10 \%$ and $90 \%$, respectively. More information on the cell parameters are given in Table I.

TABLE I

BESS CELL SPECIFICATIONS

\begin{tabular}{l|c|r} 
Nominal cell capacity & $\mathrm{C}_{\text {nom,cell }}^{\text {BESS }}$ & $100 \mathrm{Ah}$ \\
Nominal cell voltage & $\mathrm{V}_{\text {nom,cell }}^{\text {BESS }}$ & $3.3 \mathrm{~V}$ \\
Minimum cell voltage & $\mathrm{V}_{\text {cell,min }}^{\text {BESS }}$ & $3.25 \mathrm{~V}$ \\
Maximum cell voltage & $\mathrm{V}_{\text {cell,max }}^{\text {BESS }}$ & $3.35 \mathrm{~V}$ \\
Maximum cell current & $\mathrm{I}_{\text {cell, max }}^{\text {BESS }}$ & $200 \mathrm{~A}$ \\
Cell resistance & $\mathrm{R}_{\text {cell }}^{\text {BES }}$ & $0.35 \mathrm{~m} \Omega$ \\
MOSFET resistance & $\mathrm{R}_{\text {mos }}^{\text {BESS }}$ & $0.6 \mathrm{~m} \Omega$ \\
Number of cells (series) & $\mathrm{N}_{\text {cell }}^{\text {BESS }}$ & 192
\end{tabular}

The submodel BESS Battery has two inputs. The first input is the battery current $I_{\text {batt }}$, and the second input is a vector including a binary control variable $\Gamma_{\text {cell }, i}^{\mathrm{BESS}} \in\{0 ; 1\}$ for each of the cells. This variable defines, whether a cell is engaged ("1") or bypassed ("0"). Since all cells are connected in series, the individual cell current is a function of the overall battery current and the individual cell connection state, given by $I_{\text {cell }, i}^{\mathrm{BESS}}=I_{\mathrm{batt}} \cdot \Gamma_{\mathrm{cell}, i}^{\mathrm{BESS}}$. The sign convention for the current is defined so that positive values correspond to a discharging of the BESS. Hence, the individual cell SOC is calculated as

$$
S O C_{\mathrm{cell}, i}^{\mathrm{BESS}}=-\left(1 / \mathrm{C}_{\mathrm{nom}, \mathrm{cell}, i}^{\mathrm{BESS}}\right) \cdot \int I_{\mathrm{cell}, i}^{\mathrm{BESS}} \mathrm{d} t+\mathrm{SOC}_{\mathrm{init}, \mathrm{cell}, i}^{\mathrm{BESS}},
$$




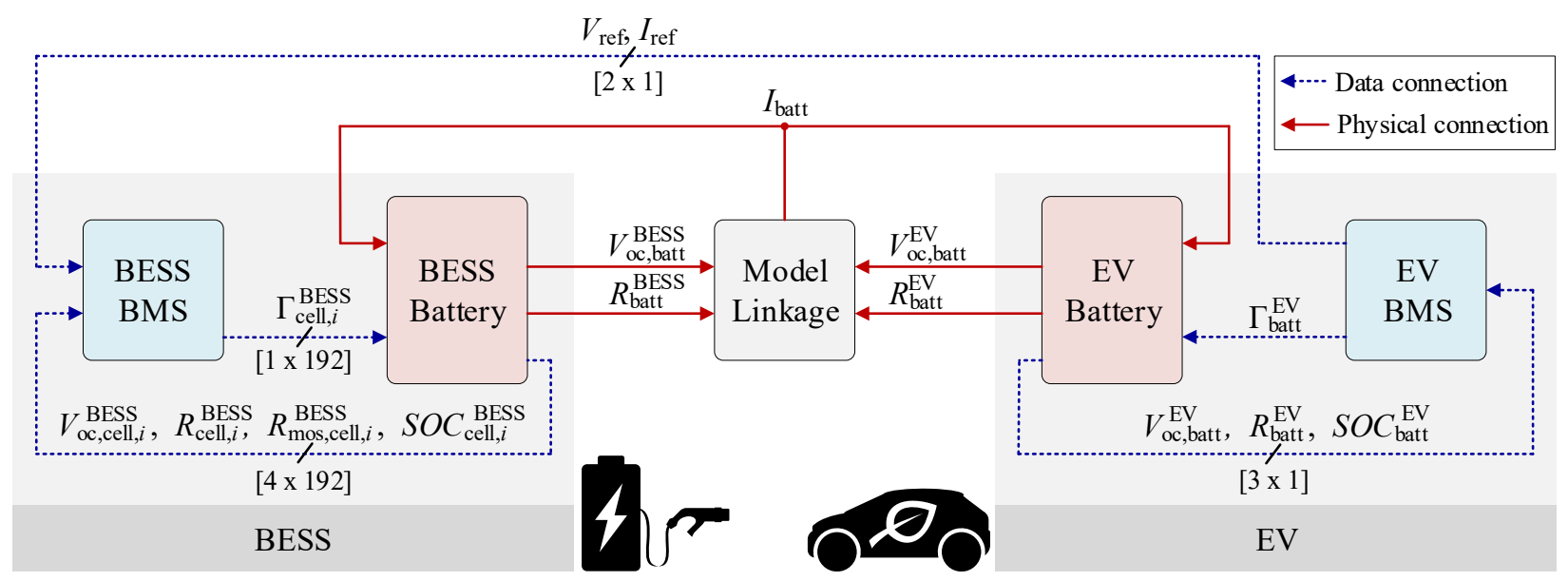

Fig. 2. Overview of the combined BESS-EV model including data connections and their physical linkage.

where $\mathrm{SOC}_{\text {init,cell, } i}^{\mathrm{BESS}}$ is the initial cell SOC. For the linkage with the EV model, only the currently engaged cells are relevant as these cells are contributing to the power transfer. Hence, the total open-circuit voltage of the BESS is given as

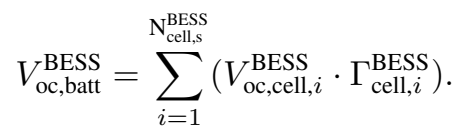

The total resistance of the BESS comprises a series connection of the individual cell resistances and the on-state resistance of the MOSFETs. Since one MOSFET is always active for each cell, the total BESS resistance is calculated as

$$
R_{\mathrm{batt}}^{\mathrm{BESS}}=\sum_{i=1}^{\mathrm{N}_{\text {cell,s }}^{\mathrm{BESS}}}\left(\mathrm{R}_{\text {cell }, i}^{\mathrm{BESS}} \cdot \Gamma_{\text {cell }, i}^{\mathrm{BESS}}\right)+\mathrm{N}_{\text {cell }}^{\mathrm{BESS}} \cdot \mathrm{R}_{\mathrm{mos}}^{\mathrm{BESS}} .
$$

While the battery open-circuit voltage and the battery resistance are used as inputs for the Model Linkage, the internal monitoring of the cells is realized by feeding back the information of the individual cell states from submodel BESS Battery into submodel BESS BMS. Based on the cell states and the reference values $I_{\text {ref }}$ and $V_{\text {ref }}$ received from the $\mathrm{EV}$, the BESS BMS estimates the optimal connection scheme according to the following two control objectives: 1) fulfilling the charging request sent by the $\mathrm{EV}$, and 2) balancing the state of charge of the different cells. Decision process and cell switching are considered with a total delay of $0.1 \mathrm{~s}$.

During each iteration, the BMS estimates the predicted cell voltages in engaged state using (1) with $I_{\text {cell }}=I_{\text {ref. }}$. The decision making algorithm then sorts the vector containing the predicted voltages of all cells in decreasing order, according to their respective cell SOC. Starting from the cells with highest SOC, the correct number of cells is determined so that the sum of the selected cell voltages is closest to the reference voltage $V_{\text {ref }}$. The selected cells will get engaged, while the remaining ones will get bypassed. Hence, the newly connected cells are always the ones with the highest SOC, which ensures keeping a balanced SOC level across the battery pack while following the charging request of the EV. The number of switching events is reduced by introducing a tolerance band defining the maximum allowed SOC difference between all cells. Consequently, the individual cells can remain in their respective connection state until they have to be switched in order to stay within the allowed SOC tolerance.

\section{EV model}

The battery submodel of the EV is based on a previous work [12]. The battery has a capacity of $\mathrm{C}_{\text {batt }}^{\mathrm{EV}}=112.6 \mathrm{Ah}$ and a nominal voltage of $\mathrm{V}_{\text {nom,batt }}^{\mathrm{EV}}=350 \mathrm{~V}$. It is equipped with an under- and over-voltage protection that allows an operative voltage range between $\mathrm{V}_{\text {min,batt }}^{\mathrm{EV}}=254.4 \mathrm{~V}$ and $\mathrm{V}_{\max , \text { batt }}^{\mathrm{EV}}=398.4 \mathrm{~V}$

The submodel $E V$ Battery has two inputs: the charging current $I_{\text {batt }}$, and the binary control variable $\Gamma_{\text {batt }}^{\mathrm{EV}} \in\{0 ; 1\}$, representing the state of the EV contactor (" 0 " if open, and " 1 " if closed). The battery states $V_{\mathrm{oc}, \text { batt }}^{\mathrm{EV}}, R_{\mathrm{batt}}^{\mathrm{EV}}$, and $S O C_{\mathrm{batt}}^{\mathrm{EV}}$ are monitored by the BMS, realized through the feedback to the submodel EV BMS. Based on this information, the EV BMS determines the optimal values for charging current and voltage and communicates the reference values $V_{\text {ref }}$ and $I_{\text {ref }}$ to the BESS. More information on the EV charging profile is given in the case study description in section IV.

\section{Model Linkage}

The Model Linkage represents the physical connection of both batteries. The inputs are the respective battery opencircuit voltages and resistances. Fig. 3 shows the equivalent circuit that is used to describe the linkage of the two systems. In order to only allow current flow from the BESS to the EV, the switch with the binary control variable $\Gamma_{\text {batt }} \in\{0 ; 1\}$ is closed ("1") for $V_{\mathrm{oc}, \text { batt }}^{\mathrm{BESS}} \geq V_{\mathrm{oc} \text {,batt }}^{\mathrm{EV}}$. Consequently, the resulting battery current is calculated as

$$
I_{\text {batt }}=\Gamma_{\text {batt }} \cdot \frac{V_{\text {oc,batt }}^{\mathrm{BESS}}-V_{\mathrm{oc}, \mathrm{batt}}^{\mathrm{EV}}}{R_{\text {batt }}^{\mathrm{BESS}}+R_{\mathrm{batt}}^{\mathrm{EV}}} .
$$




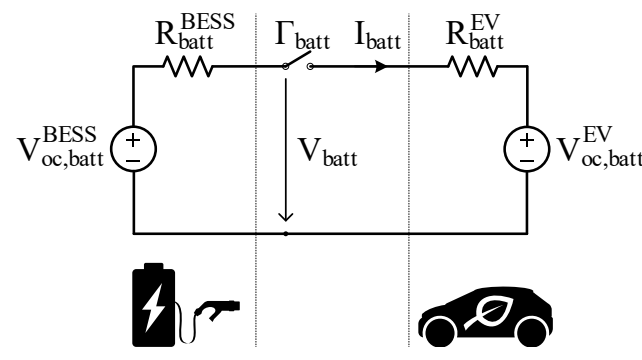

Fig. 3. Equivalent circuit for the model linkage.

The current $I_{\text {batt }}$ is the output of the Model Linkage and is used as an input for the submodels BESS Battery and EV Battery.

\section{CASE STUDY}

The case study aims at testing the proposed BESS concept with respect to the defined control objectives. Based on the introduced model, a simulation of a complete fast-charging process is performed. The initial SOC of the EV is set to $0 \%$, and the target SOC is $100 \%$. During the charging process, the reference values $V_{\text {batt }}$ and $I_{\text {batt }}$ sent by the EV follow the progressions shown in Fig. 4.

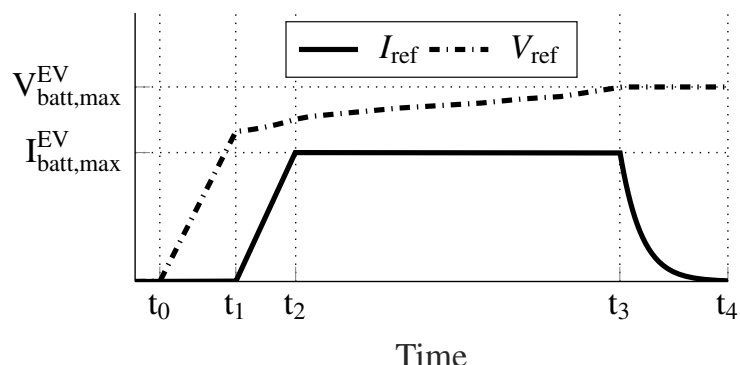

Fig. 4. Qualitative fast-charging profile for the case study.

It is assumed that at $\mathrm{t}_{0}=0 \mathrm{~s}$ authentication and information exchange between EV and BESS were successfully completed and that the EV contactor is closed. The charging process is divided into four phases:

1) Voltage ramp-up $\left(\mathrm{t}_{0}-\mathrm{t}_{1}\right)$ : The $\mathrm{EV}$ requests from the BESS to ramp up the output voltage with $2 \mathrm{~V} / \mathrm{s}$. Current flow is still prevented at this point. $V_{\text {ref }}$ is increased until is reaches the EV battery voltage. At $t=\mathrm{t}_{1}$ the voltage ramp-up is completed and the power transfer can start.

2) Current ramp-up $\left(\mathrm{t}_{1}-\mathrm{t}_{2}\right)$ : The requested charging current $I_{\text {ref }}$ is increased by $1 \mathrm{~A} / \mathrm{s}$ until it reaches its maximum value $\mathrm{I}_{\mathrm{batt}, \max }^{\mathrm{EV}}=112.6 \mathrm{~A}$, which corresponds to a charging rate of $1 \mathrm{C}$. During this phase, the optimal charging voltage is calculated as $V_{\text {ref }}=V_{\text {oc,batt }}^{\mathrm{EV}}+R_{\text {batt }}^{\mathrm{EV}} \cdot \mathrm{I}_{\text {ref }}$.

3) Constant current charging $\left(\mathrm{t}_{2}-\mathrm{t}_{3}\right)$ : The reference current is kept constant at its maximum. The reference voltage $V_{\text {ref }}$ is calculated equally as in phase 2 .
4) Constant voltage charging $\left(\mathrm{t}_{3}-\mathrm{t}_{4}\right)$ : The reference voltage is kept constant at $\mathrm{V}_{\mathrm{batt} \text { max }}^{\mathrm{EV}}$, while the reference current decreases according to $I_{\text {ref }}=\left(\mathrm{V}_{\text {batt,max }}^{\mathrm{EV}}-V_{\text {oc,batt }}^{\mathrm{EV}}\right) / R_{\text {batt }}^{\mathrm{EV}}$. At $t=\mathrm{t}_{4}$ the charging is completed.

At the beginning of the case study, all BESS cells are balanced with $\mathrm{SOC}_{\text {init,cell }}^{\mathrm{BESS}}=90 \%$, corresponding to $\mathrm{V}_{\text {cell,max }}^{\mathrm{BESS}}$. The tolerated maximum SOC difference between all cells is set to $5 \%$. The simulation is executed with a fixed time-step of $0.1 \mathrm{~s}$.

\section{Simulation Results}

In this section, the simulation results for the proposed case study are presented. First, the general output of the simulation is described. Then, the performance of the BESS is evaluated with respect to its two objectives: fulfilling the charging request sent by the EV, and balancing the SOC of the individual BESS cells. The section further covers a discussion of the results including the limitations of the study.

\section{A. General Outcome}

Fig. 5 provides an overview of the progressions of voltage, current, and SOC, for the completed charging procedure. In their respective graphs, the curves of $V_{\text {batt }}$ and $I_{\text {batt }}$ are compared to their reference value sent by the EV. While the deviation from the reference values appears to be marginal in case of the voltage profile, the progression of the charging current shows clear deviations from the EV request. This will be further analysed in subsection V-B. In Fig. 5 c., the SOC progressions for both the BESS and the EV are presented. With the start of the current ramp-up, the SOC of the EV begins to increase and becomes linear at the beginning of the constant current charging phase. After entering into the constant voltage charging phase, the slope decreases due to the declining charging current and the SOC converges towards the targeted $100 \%$. The SOC progression of the BESS is analysed in subsection V-C.

The charging process is completed after $69 \mathrm{~min}$, with a total energy transfer from the BESS to the EV of $39.80 \mathrm{~kW}$. The power losses of the MOSFETs amount to $1.42 \mathrm{~kW}$, corresponding to $3.66 \%$ of the transferred energy. These losses could be reduced by designing the switches with several MOSFETs in parallel to share the current. Another improvement with respect to the battery operation is to bypass complete modules when none of their cells is engaged. This decreases the power losses significantly, as for each bypassed module, the power losses of 24 MOSFETs are avoided.

\section{B. Fulfillment of Charging Request}

Due to the wide range of the BESS voltage, a total view of the charging process as presented in Fig. 5 a. does not show any differences between $V_{\text {batt }}$ and $V_{\text {ref. Therefore, Fig. } 6}$ provides a closer view on the voltage progressions for an exemplary time interval between $380 \mathrm{~s}$ and $480 \mathrm{~s}$. 
a)

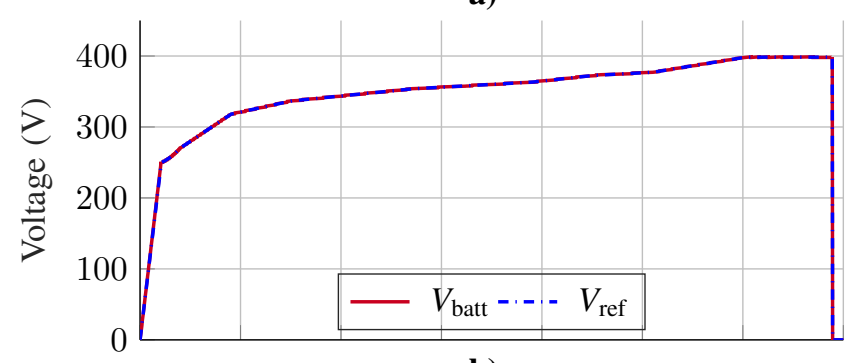

b)

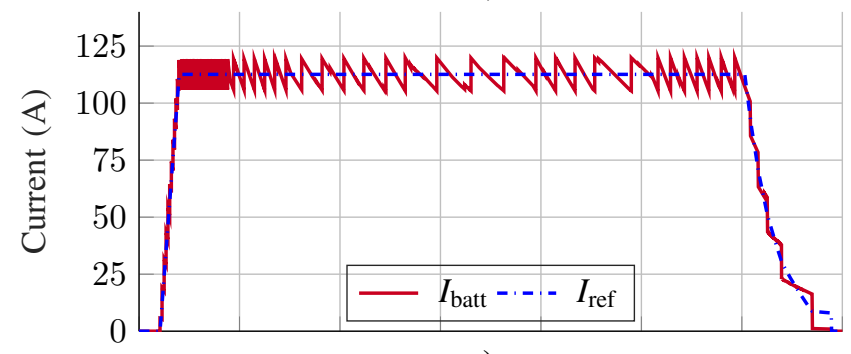

c)

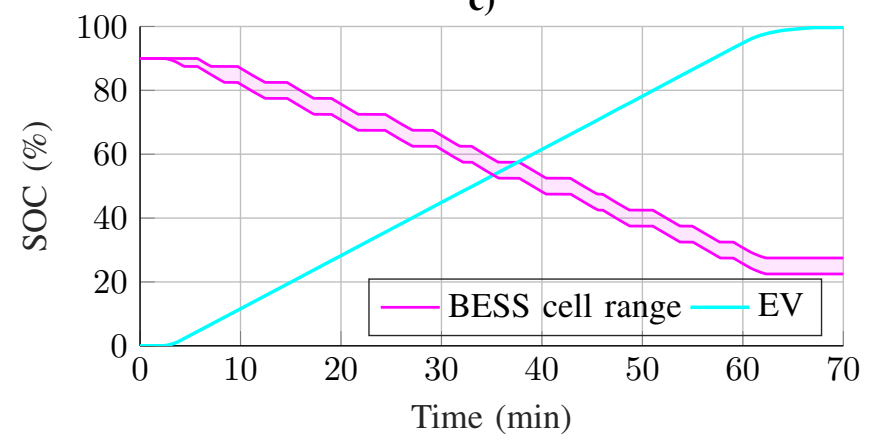

Fig. 5. Progressions of a) voltage, b) current, and c) SOC during the fastcharging process

Besides the voltages $V_{\text {batt }}$ and $V_{\text {ref }}$, the figure also shows the open-circuit voltages of both the BESS and the EV model. The previously introduced equivalent circuit in Fig. 3 gives the relation between the voltages shown in the graph. The voltage drop $V_{\mathrm{oc}, \text { batt }}^{\mathrm{BESS}}-V_{\text {batt }}$ is due to the resistance $R_{\mathrm{batt}}^{\mathrm{BESS}}$, and the voltage drop $V_{\text {batt }}-V_{\text {oc,batt }}^{\mathrm{EV}}$ is due to the resistance $R_{\text {batt }}^{\mathrm{EV}}$. As seen in the graph, $V_{\mathrm{oc}, \text { batt }}^{\mathrm{EV}}$ increases continuously while the increment of $V_{\text {oc,batt }}^{\text {BESS }}$ occurs in steps. The steps are a result of the adaptive cell switching performed by the BESS. Through connecting the appropriate number of cells, the BESS BMS can control $V_{\text {batt }}$ in order to meet the charging request of the EV. During the shown time interval, five additional cells were engaged, indicated by the corresponding number of voltage steps.

The graph shows that the BESS is able to follow the reference voltage with a high precision. Since the voltage control is based on connecting and disconnecting individual cells, the lowest precision is achieved when the cell voltages are at the maximum. According to (1), this is the case when the cells have their highest $V_{\mathrm{oc}, \mathrm{Bell}}^{\mathrm{BES}}$ and at the same time the current is minimal. With respect to the whole charging process, these conditions are met at the beginning of the current ramp-

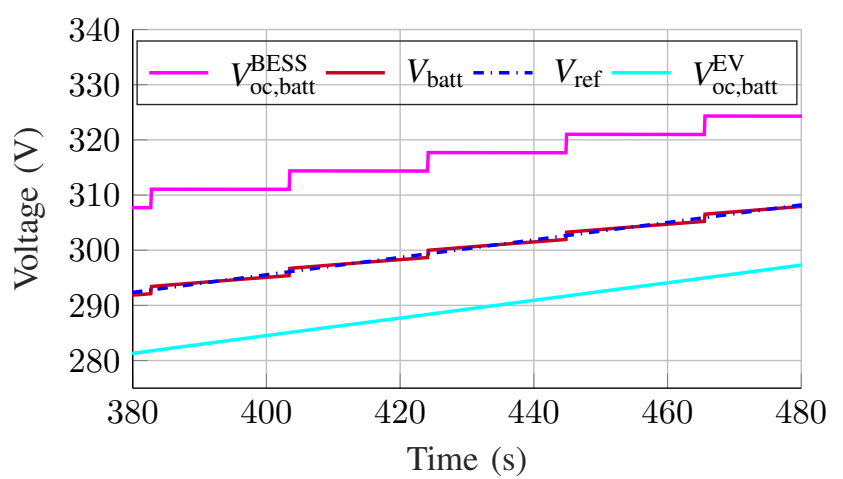

Fig. 6. Enlarged view on model voltages for an exemplary time interval

up, where the BESS cells are still fully charged. For the simulated scenario, the maximum observed deviation from the reference value was $\left|V_{\text {batt }}-V_{\text {ref }}\right|_{\max }=1.67 \mathrm{~V}$. The charging standard [11] specifies the maximum voltage deviation during the power transfer as $5 \%$ of the requested voltage. The lowest tolerance is therefore given at the beginning of the current ramp-up with $254.4 \mathrm{~V} \cdot 5 \%=12.72 \mathrm{~V}$, since the reference voltage is the lowest at this point. Additionally, periodically occurring voltage ripples shall not exceed $5 \mathrm{~V}$. Consequently, the precision of the presented voltage control concept is sufficient with regard to the made assumptions.

In contrast to the voltage, the deviations of the actual current from its reference seem considerably larger. According to (5), the current is a function of the voltage difference $V_{\mathrm{oc}, b a t t}^{\mathrm{BES}}-V_{\mathrm{oc}, \text { batt }}^{\mathrm{EV}}$ divided by the total resistance. Consequently, the voltage steps caused by the cell switching are directly affecting the charging current. When $V_{\mathrm{oc}, \text { batt }}^{\mathrm{EV}}$ is increasing in a linear fashion and $V_{\text {oc,batt }}^{\mathrm{BESS}}$ is increasing in steps, the charging current will follow the inverse sawtooth progression seen in Fig. 5 b., consisting of a positive step followed by a linear decrease. In the present study, the peak-to-peak values reached up to $15.1 \mathrm{~A}$. During the constant voltage charging phase, where $V_{\text {oc,batt }}^{\mathrm{EV}}$ is approaching its maximum value, the BESS is decreasing $V_{\text {oc,batt }}^{\mathrm{BESS}}$ by successively disconnecting cells in order to follow the decreasing reference current. This then leads to the negative current steps during this charging phase, as seen in Fig. 5 b. The charging standard [11] specifies the maximum current tolerance for $I_{\text {ref }}<50 \mathrm{~A}$ as $\pm 2.5 \mathrm{~A}$, and for $I_{\text {ref }} \geq 50 \mathrm{~A}$ as $\pm 5 \%$. Furthermore, current ripples occurring with a frequency of below $10 \mathrm{~Hz}$ must not exceed 1.5 A between positive peak top and negative peak top at full scale output. Both limits are clearly exceeded throughout the charging process. Consequently, the control concept presented in this study does not meet the current requirements specified in [11].

The results show, that additional techniques are required to reduce the current deviations. A possible solution could be to further improve the granularity of the output voltage, since the voltage steps are directly reflected in the progression of the charging current. One conceptional measure with respect 
to the BESS design is to use cell types with a lower opencircuit voltage. Another solution is to smoothen the BESS output voltage by connecting a DC-DC converter with an voltage range of $V \in\left[0, V_{\mathrm{oc} \text {,cell }}^{\mathrm{BESS}}\right]$ in series to the battery pack. The output voltage of the converter could be controlled by the BMS in order to compensate the deviations between $V_{\text {batt }}$

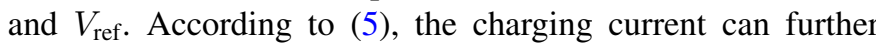
be controlled by adjusting an additional series-connected variable impedance. Based on the introduced Simulink model, future studies could aim at comparing different approaches for complementing the reconfigurable battery concept in order to achieve a sufficient current control.

\section{SOC Balancing}

Fig. 5 c. shows the overall SOC level of the BESS cells during the charging process. The upper line represents the maximum cell SOC and the lower line represents the minimum cell SOC present in the system. The graph demonstrates, that the maximum SOC difference between all cells did not exceed the targeted value of $5 \%$ throughout the whole charging process. Therefore, it can be concluded that the objective of balancing the cell SOCs is met. The overall SOC level follows a step-like decrease because the controlling algorithm uses the flexibility emerging from the provided tolerance band of $5 \%$ to minimize the number of switching events per cell. An engaged cell always stays engaged until its SOC decreases to $5 \%$ below the maximum cell SOC present in the battery pack. After getting disconnected, it remains bypassed until it becomes the cell with the maximum SOC due to the discharging of other cells. This behaviour leads to the temporary plateaus visible in the graph. At the end of the fast-charging scenario, the overall SOC level of the cells reached an averaged value of $24 \%$.

\section{Model Limitations}

For prospective analyses, the existing model is to be further improved. With respect to the shown results, it is important to consider that the presented model does not describe any transient response when connecting or disconnecting individual cells. Although the current ripples seen in the results were caused by the limited voltage granularity, connecting and disconnecting of individual cells might still cause additional transient effects that can lead to unacceptable voltage and current progressions. Hence, also capacitances and inductances of the respective circuit elements should be included in an improved model. Furthermore, thermal dependencies and switching delays are to be considered.

With regard to the presented control algorithm, a more sophisticated version could also include the temperature and the state-of-health of the individual cells. Thus, preventive measures against overheating and ageing of individual cells are considered in the decision-making. Consequently, possible effects of the cell switching on the battery life-time can be analyzed.

\section{CONCLUSIONS}

In the present study, we analyse the capability of a BESS with reconfigurable cell topology to provide charging power to an EV. In the proposed fast-charging scenario, the BESS was directly coupled with the EV, without any power converter interconnecting the two units. By engaging and bypassing individual cells, the BESS was following two control objectives: 1) fulfilling the voltage and current requests sent by the EV, and 2) balancing the cell SOCs across the battery pack. The simulation results showed that the BESS was able to keep all cell SOCs within the tolerance band throughout the entire charging process. Furthermore, the voltage request of the EV was met in a satisfactory manner. However, the approach of cell switching proved to be not sufficient for fulfilling the current request. The presented control concept is therefore to be complemented with a suitable current control in order to comply with recent charging standards. Future studies could focus on more sophisticated control concepts, with additional objectives such as maintaining thermal stability and improving the life-time of the BESS.

\section{REFERENCES}

[1] P. Kasten, J. Bracker, M. Haller, and J. Purwanto, "Assessing the status of electrification of the road transport passenger vehicles and potential future implications for the environment and European energy system," OEKO-Institut, Transport \& Mobility Leuven, TNO, Trinomics, Specific Contract on Framework Contract EEA/ACC/13/003, Lot-1. Final report - Task 2, 2016.

[2] E. Emilsson, and L. Dahllöf, "Lithium-Ion vehicle battery production status 2019 on energy use, CO2 emissions, use of metals, products environmental footprint, and recycling," 2019, doi:10.13140/RG.2.2.29735.70562.

[3] M. Yilmaz and P. T. Krein, "Review of the impact of vehicle-to-grid technologies on distribution systems and utility interfaces," in IEEE Trans. Power Electron., vol. 28, no. 12, pp. 5673-5689, Dec. 2013.

[4] L. Calearo, A. Thingvad, K. Suzuki, and M. Marinelli, "Grid loading due to EV charging profiles based on pseudo-real driving pattern and user behavior," in IEEE Trans. Transport. Electrific., vol. 5, no. 3, pp. 683-694, Sept. 2019.

[5] D. De Simone and L. Piegari, "Integration of stationary batteries for fast charge EV charging stations," Energies, vol. 12, issue 24, 2019.

[6] T. Gabderakhmanova, J. Engelhardt, J. M. Zepter, T. M. Sørensen, K. Boesgaard, H. H. Ipsen, M. Marinelli, "Demonstrations of DC microgrid and virtual power plant technologies on the Danish island of Bornholm," 2020 Proceedings of the 55th International Universities Power Engineering Conference (UPEC), pp. 1-6, Torino, 1-4 Sep. 2020.

[7] S. Ci, N. Lin and D. Wu, "Reconfigurable battery techniques and systems: a survey," in IEEE Access, vol. 4, pp. 1175-1189, 2016, doi: 10.1109/ACCESS.2016.2545338.

[8] J. Gallardo-Lozano et. al., "Battery Equalization Active Methods," in J. Power Sources, Vol. 246, pp. 934-949, January 2014.

[9] T. Morstyn, M. Momayyezan, B. Hredzak, and V. G. Agelidis, "Distributed Control for State-of-Charge Balancing Between the Modules of a Reconfigurable Battery Energy Storage System," in IEEE Trans. Power Electron., vol. 31, no. 11, pp. 7986-7995, Nov. 2016.

[10] S. Ci, J. Zhang, H. Sharif, and M. Alahmad, "A Novel Design of Adaptive Reconfigurable Multicell Battery for Power-Aware Embedded Networked Sensing Systems," IEEE GLOBECOM 2007 - IEEE Global Telecommunications Conference, Washington, DC, 2007, pp. 1043 1047.

[11] Electric vehicle conductive charging system - Part 23: DC electric vehicle charging station, DS/EN 61851-23:2014/AC:2016, 2016.

[12] L. Calearo, A. Thingvad, and M. Marinelli, "Modeling of Battery Electric Vehicles for Degradation Studies," 2019 54th International Universities Power Engineering Conference (UPEC), Bucharest, Romania, pp. 1-6. 